\title{
A Case Report of Tenosynovial Giant Cell Tumor in an Unusual Location: The Supraclavicular Region
}

\author{
Fotini Ieridou*, Gabriel Tsiropoulos and Jannis Constantinidis \\ Department of Otolaryngology, AHEPA Hospital, Aristotle University of Thessaloniki, Greece
}

*Corresponding author: Fotini Ieridou, Otolaryngology Department, AHEPA Hospital, Aristotle University of Thessaloniki, Greece

\begin{abstract}
Tenosynovial giant cell tumor (TSGCT) is a benign tumor that commonly presents in the upper limb joints and hands and less frequently occurs in the lower extremities. Usually they arise from synovium or tendon sheath. The aim of this article is to present an unusual location of TSGCT of the supraclavicular region in a young patient.
\end{abstract}

Keywords: Tenosynovial, giant cell tumor, supraclavicular region

Abbreviations: TSGCT: Tenosynovial Giant Cell Tumor, CSFIR: Colony Stimulating Factor 1 Receptor, WHO: World Health Organization

\section{Introduction}

Tenosynovial giant cell tumor (TSGCT) is a benign tumor that commonly presents in the upper limb joints and hands and less frequently occurs in the lower extremities. Usually they arise from synovium or tendon sheath $[1,2]$.TSGCT is divided into two main subtypes: the localized type that is otherwise known as giant cell tumor of tendon sheath that is well circumscribed and occurs in small joints e.g. fingers; it has a local recurrence rate of about (4$30 \%$ ) [1,2]. The second type is the diffuse TSCGT otherwise known as pigmented villonodular synovitis that is poorly circumscribed. It occurs usually in large joints and is more aggressive than type 1 TSCGT and has a recurrence rate of $18-50 \%$. Type 2 TSCGT is cured with radical excision [2]. In this article, we report an unusual location of TSGCT of supraclavicular region, which is the second case that is presented in the literature [3].

\section{Case Report}

A 16-years old woman presented with a six-month history of slowly growing painless mass in left supraclavicular region. That was initially suspicious of a pathological lymph node, neurinoma or a hematological disorder (lymphoma). Neurological and vascular examination were unremarkable and laboratory values were within normal range. The patient underwent an ultrasound guided fine needle aspiration of the tumor that showed benign large multinucleated giant cells, histiocyte and xanthoma cells positive for CD68 by immunohistochemistry. The tumor showed no necrosis. The patient underwent further investigations including magnetic resonance imaging and angiography of neck (MRI and MRA scans). The results showed a $23 \times 17 \times 35 \mathrm{~mm}$ left supraclavicular mass that distorted scalene muscles in this region with normal vascular anatomy (Figure 1). The patient had an elective operation and the tumor was totally excised from level $5 \mathrm{~b}$ left neck region and 2 lymph nodes were also removed (Figure 2). Postoperatively, the patient had an unremarkable recovery and she was discharged three days later. The histology confirmed the diagnosis of Tenosynovial giant cell tumor of left supraclavicular region. The lymph nodes showed no pathology. 


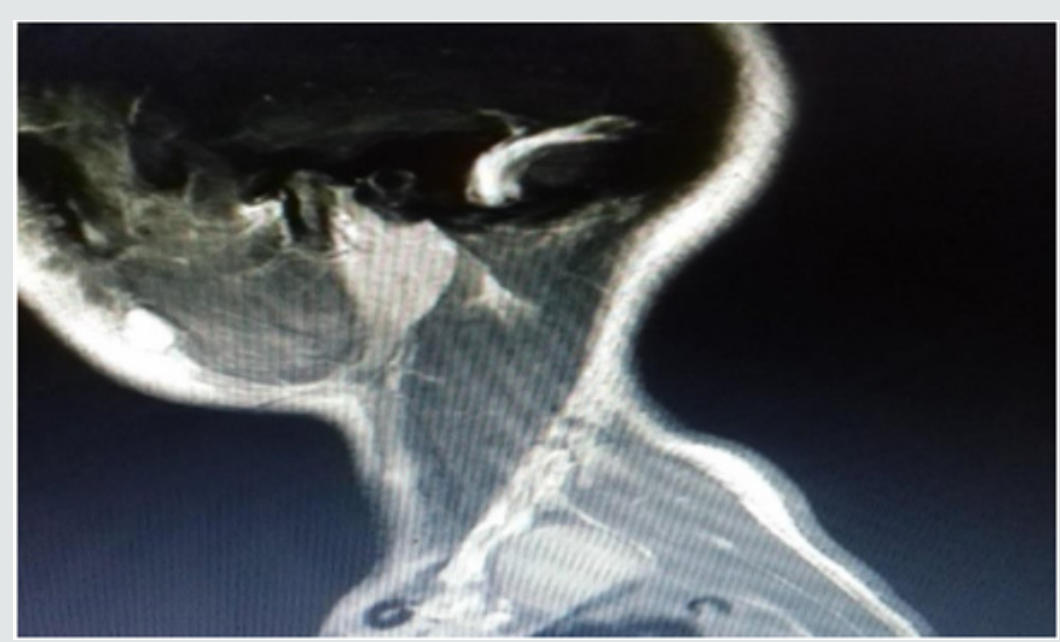

Figure 1: Sagittal view MRI scan neck showing left posterior triangle mass.

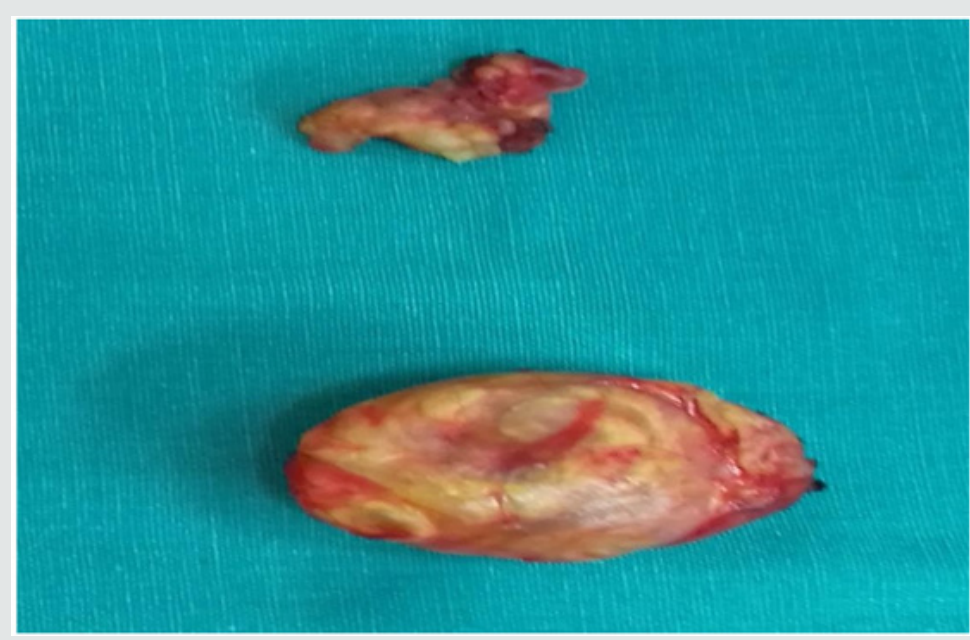

Figure 2: Left supraclavicular tumor (bottom) and tissue with 2 lymph nodes(top).

\section{Discussion}

TSGCT or giant cell tumor of tendon sheath is a rare benign lesion involving joint synovia, bursae or tendon sheath. The annual incidence of TSGCT is 1.8 per million. It may be intra-articular or extra-articular and can be classified as local or diffuse lesions $[1,4]$. TSGCT is more common in women and the ratio is male to female 1:1.5 with average age between (30-50yrs) [1]. TSGCT may also affect children but the incidence for both localized and diffuse types is rare [5,6]. TSGCT is a monoarticular disease affecting typically large joints e.g. the knee. The second most affected joints are the hand and wrist followed by the hip and ankle. Common symptoms described in literature include pain, stiffness and swelling of the affected joint [7]. The tumor that we present is in an unusual site and according to literature is the second one described in the supraclavicular region [3]. Malignant tumors such as synovial sarcoma and benign tumors should be kept in mind as potential differential diagnosis [8,9]. Multinucleated giant cells are a major clue for diagnosis of TSGCT. On immunohistochemistry the histiocyte cells are positive for markers like CD68, CD45 and CD163 like it occurred in our case [10]. World Health Organization (WHO) classified TSGCT as a benign tumor. There is debate however whether it is a true neoplasm as studies have supported the presence of translocation in chromosome 1p11-13 and overexpression of macrophage colony stimulating factor 1 receptor (CSFIR) [7,11]. Initial treatment is surgical resection and if recurrence occurs then additional radiation therapy, synovectomy and external beam radiation therapy are recommended [12].

\section{Conclusion}

TSGCT is a benign tumor of tendon sheath of slow progression. As TSGCT in our case is located in an unusual location it is difficult to diagnose it. Diagnosis requires MRI scan and histologic confirmation. Initial treatment is surgical resection of the tumor. Recurrence rate does occur in TSGCT and therefore a close follow up is recommended.

\section{Conflict of Interest}

The authors have no conflict of interest to declare. 


\section{References}

1. De St Aubain Somerhausen N van de Rijn M (2013) Tenosynovial giant cell tumor diffuse type in: WHO classifications of tumors of soft tissue and bone (Fletcher CDM BJ, Hogendourn PCW, Mertens F, editors) $4^{\text {th }}$ edition Geneva Lyon, IARC Press pp. 100-103.

2. Mastboom MJL (2019) Surgical outcomes of patients with diffuse type tenosynovial giant cell tumors: an international retrospective cohort study. Lancet Oncol 20(6): 877-886.

3. Plumnorasamat S, Jinawat A (2019) Giant cell tumor of tendon sheath in supraclavicular region: cytological aspect of a common tumor in an uncommon location. The Bangka Medical journal 15(1): 97-99.

4. Nielsen GP, O Connel JX (2010) Tumors of synovial tissue Bone and soft tissue pathology Philadelphia PA. Elsevier Inc pp. 255-261.

5. Tel A, Spinzia A, Boggio M (2012) Diffuse tenosynovial giant cell tumor of temporomandibular joint. Int J Oral Max Surg 41(3): 321-323.

6. Mastboom M (2018) Tenosynovial giant cell tumors in children: a similar entity compared with adults. Clin Orth Rel Res 476(9): 1803-1812.
7. Cupp JS (2007) Translocation and expression CSF1 in pigmented villonodular synovitis tenosynovial giant cell tumor rheumatoid arthritis and other reactive synovitides. Am J Surg Path 31(6): 970-976.

8. Sun C, Sheng W, Yu H, Han J (2012) Giant cell tumor of the tendon sheath: a rare case in left knee of 15-year-old boy. Oncology letters 3(3): 718720 .

9. Lowyck H, Smet LD (2006) Recurrence rate of giant cell tumors of tendon sheath. Eur J Plat Surg 28(6): 385-388.

10. Vershoor A (2018) Incidence and demographics of giant cell tumors of bone in Netherlands. Acta Orth 89(5): 570-574.

11. Gelhorn HC (2016) Patient reported symptoms of Tenosynovial giant cell tumors. Clin Ther 38(4): 778-793.

12. Heyd R, Seengenschmiedt MH, Miche $O$ (2011) The role of extrabeam radiation therapy in adjuvant treatment of pigmented villonodular synovitis. Z Orth Unfall 149(6): 677-682.

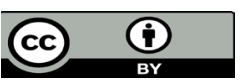

This work is licensed under Creative Commons Attribution 4.0 License

To Submit Your Article Click Here: Submit Article

DOI: $10.32474 /$ SJ0.2020.04.000183

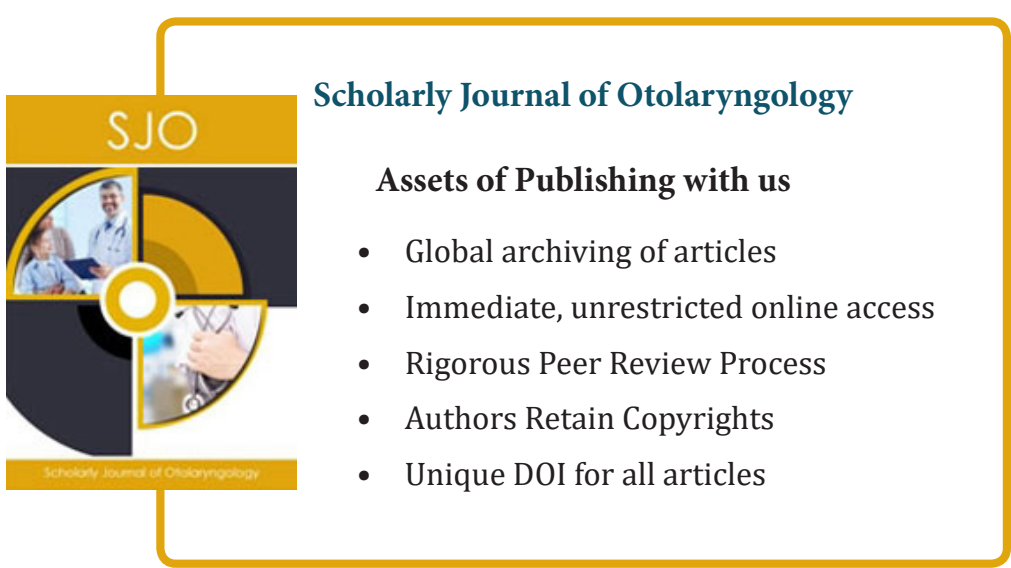

